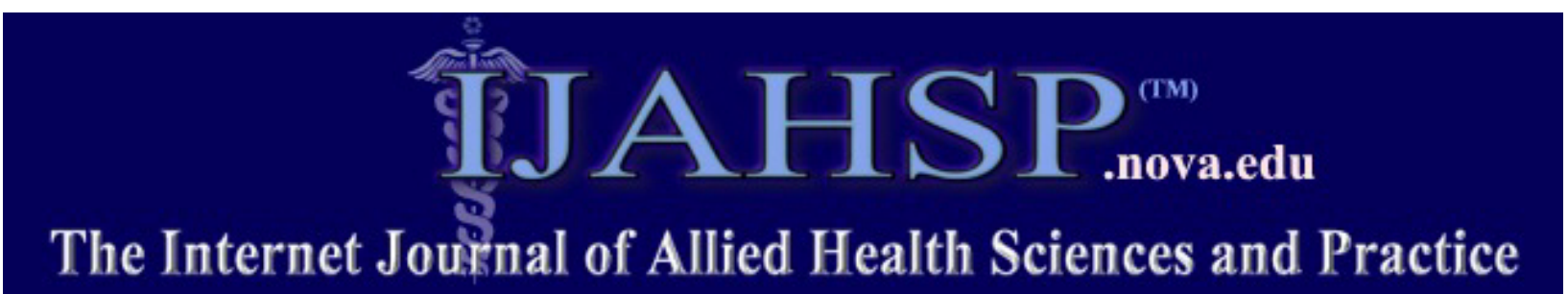

A Peer Reviewed Publication of the College of Health Care Sciences at Nova Southeastern University

Dedicated to allied health professional practice and education

http://ijahsp.nova.edu Vol. 10 No. 4 ISSN 1540-580X

\title{
Evidence-Based Practice (EBP) in Rehabilitative Physiotherapy
}

\author{
Chris Cimoli, B.PHYS, MHA \\ Senior Physiotherapist, Royal Talbot Rehabilitation Centre, Austin Health, Melbourne
}

Australia

CITATION: Cimoli C. Evidence-Based Practice (EBP) in Rehabilitative Physiotherapy. The Internet Journal of Allied Health Sciences and Practice. Oct 2012. Volume 10 Number 4.

\begin{abstract}
Evidence-Based Practice (EBP) is considered to be an essential component of clinical service delivery in healthcare. Australian physiotherapists have access to a wide range of resources to support the implementation of EBP. However, research indicates variability in how physiotherapists apply EBP with a range of factors affecting the successful implementation of EBP into everyday clinical practice. Using survey methodology, this study examined whether participation in an EBP professional development workshop is an effective strategy to enhance knowledge, attitudes and behaviours associated with EBP of physiotherapists working in a rehabilitation setting. Results revealed that nearly one third of participants rated their EBP knowledge and skills at a higher level following attendance at the workshop. An increase in the frequency in EBP related activities by physiotherapists including conducting searches and reading or reviewing research literature to support clinical decision-making was observed following attendance at the EBP workshop. Participants' opinions of the value of EBP in improving the quality of patient care were noted to be more positive following the workshop. This small-scale study provides some promising results regarding the positive effects that designated EBP professional development can have on knowledge, attitudes, and behaviours of physiotherapists in their application of EBP. The elements that are required to further support and sustain a strong EBP culture amongst physiotherapists working in rehabilitation are also discussed.
\end{abstract}

\section{INTRODUCTION}

Evidence-Based Practice (EBP) is defined as the application and integration of the best available research evidence with clinical expertise and patient values by healthcare professionals delivering healthcare services. ${ }^{1}$ Evidence has shown that patient outcomes can be improved where health professionals have an evidence-based approach to clinical care. ${ }^{1}$ For allied health professions such as physiotherapy, various resources have been developed to facilitate the implementation of EBP into everyday clinical reasoning and decisions about treatment including providing clinicians with greater access to journals, evidence summaries, and systematic reviews..$^{2-11}$

Many physiotherapists are aware of EBP principles and the range of resources that are available to support the application of EBP in clinical practice. Physiotherapists have also been found to have a positive attitude toward EBP.3,5,6 However, research has shown that in many instances, physiotherapists continue to base their clinical decisions on knowledge they have acquired during their entry-level training rather than considering the contemporary evidence when selecting the best course of management for a patient. ${ }^{2-4}$

Various factors have been found to limit the application of EBP in physiotherapy practice. ${ }^{2-17}$ Attaining the knowledge and skills to critically appraise the research or conduct a comprehensive database search has been identified as important factors. ${ }^{2-17}$ Physiotherapists frequently report low levels of self-confidence in their abilities to undertake either of these activities. ${ }^{2-17}$ Time is 
also reported to be one of the most critical elements to the successful implementation of an EBP approach to support clinical decision-making in physiotherapy practice. ${ }^{1-17}$ Clinicians need to have adequate time to invest in EBP activities.

To address the recognised issue of time, many researchers have suggested that physiotherapists need to be provided with opportunities to participate in professional development activities that specifically target EBP.1-17

The current study was undertaken to explore whether providing physiotherapists working in the rehabilitation setting with the opportunity to attend a targeted EBP professional development workshop would lead to improved knowledge, behaviours and attitudes towards EBP.

\section{METHODS}

This study was undertaken using a quantitative study design applying survey methodology. Ethics approval was obtained for this study from Austin Health Human Ethics and Research Committee (HREC) and La Trobe University, Faculty Human Ethics Committee.

\section{Participants}

A convenience sample of physiotherapists was utilised for this study. Participants satisfied the inclusion criteria of currently practicing and holding national registration as a physiotherapist in Australia. Participants were invited to participate in the study on two occasions, using two methods: verbally via a physiotherapy departmental staff meeting, and via an email sent to all physiotherapy staff. A participation rate of $74 \%(n=17)$ was obtained. All participants completed the participant information statement and provided written consent. The participants all worked within the same rehabilitation hospital. The rehabilitation hospital delivered services to specific groups of patients including those who have sustained spinal cord injury, undergone orthopaedic surgery, and amputation as well as those who have acute or progressive neurological disorders. The sample comprised 2 men and 15 women. The number of years of clinical experience as a physiotherapist ranged from 2 to 27 years $(\mu=$ 11 years).

\section{Survey}

A survey was developed to collect the data for this study. Literature reviews were conducted to examine surveys used in previous studies examining physiotherapy practice and identify key areas for investigation and response models for the survey items. ${ }^{2-4,16,17}$ The survey was pilot tested to investigate and address any issues regarding readability, clarity, grammatical structure, and interpretation. The individuals involved in the pilot testing had considerable experience in both developing and conducting surveys for health professionals.

The final survey was formatted as a paper-based survey and consisted of 19 questions to examine the areas of interest:

- $\quad$ Current EBP activity (5 items)

- Perceived EBP skills (4 items)

- Recognition of EBP terminology and search strategies (3 items)

- Beliefs and attitudes to EBP (4 items)

- Local barriers to EBP (2 items)

- Year of graduation as a physiotherapist (1 item)

Refer to Appendix A for a complete version of the survey.

Most survey items included four and five response options (4 and 5-point Likert scales). Two questions concerning local barriers to EBP required respondents to assign a numerical rank order to the items presented.

\section{EBP Professional Development Workshop}

An EBP professional development workshop was designed specifically for this study. This workshop was presented by two recognised experts in the field of EBP: one of the presenters was the EBP clinical leader in a tertiary-level health service and primary author of numerous publications in peer-reviewed journals, and the other presenter was a medical librarian who had been involved in conducting EBP training for medical and allied health professionals at both entry-level and post-graduate level and co-developer of a number of web-based EBP resources. Prior to the workshop, participants were provided with a package of pre-reading material. This package comprised some EBP background reading prepared by the co-presenters. It also included an article from a peer-reviewed journal related to physiotherapy practice selected in consultation with the two workshop presenters. This article was used to guide group discussion within the critical appraisal component of the workshop program. The workshop was three hours in duration and was delivered via a combination of didactic presentations (90 minutes), group discussion (45 
minutes), and practical skills exercises including database searching (45 minutes). The workshop addressed topics such as formulation of clinical questions, sources of evidence, access and search strategies for EBP, tools and processes for critically appraising research, and the application of EBP into clinical practice.

\section{Data Collection}

This study consisted of two rounds of data collection. Participants were asked to complete the survey prior to attending the workshop (pre-workshop survey data), and again six weeks later after attending the EBP workshop (post-workshop survey data). Participants received the surveys via the internal mail and were asked to return their surveys to the researcher via the internal mail. Surveys were coded with an individual numerical identifier (number between 1-17) in order that the data collected was deidentified. A response rate of $100 \%$ was obtained for both rounds of data collection (the pre-workshop and post-workshop surveys).

\section{Data Analysis}

EpiData Analysis program was used to conduct the data analysis. Descriptive statistics were used to summarise the data. The percentage of responses for each response option for each survey item for pre- and post-workshop data, was calculated.

\section{RESULTS}

\section{EBP Activity}

\section{Figure 1. EBP Activity - Use of Literature and Research in Clinical Decision Making}

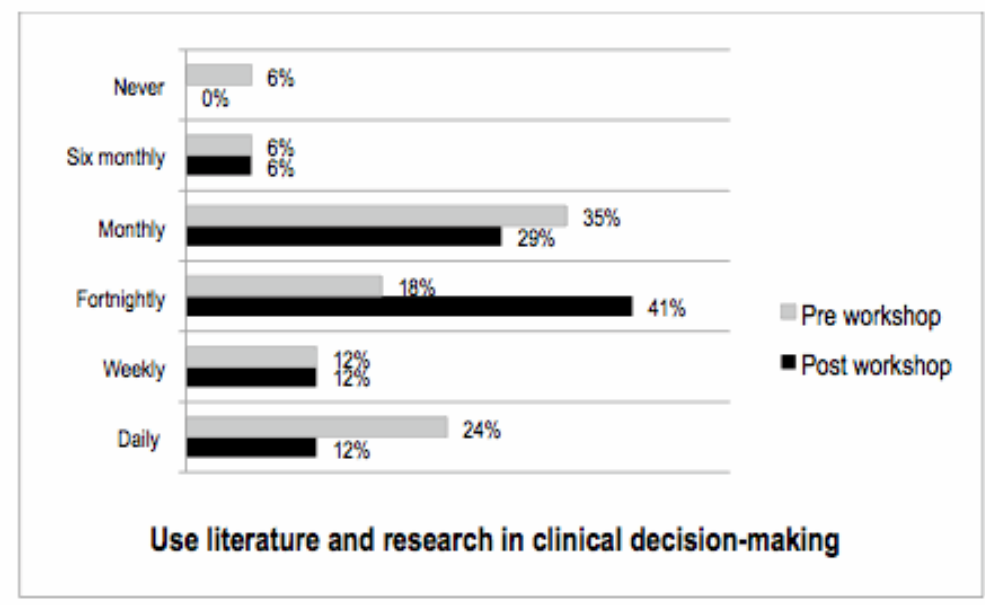

Fortnightly, weekly and daily categories were collapsed and revealed an increase in the frequency of using literature and research in clinical decision-making from $54 \%$ pre- workshop to $65 \%$ after attending the workshop.

Figure 2. EBP Activity - Conduct Searches for Clinical Practice Relevant Research

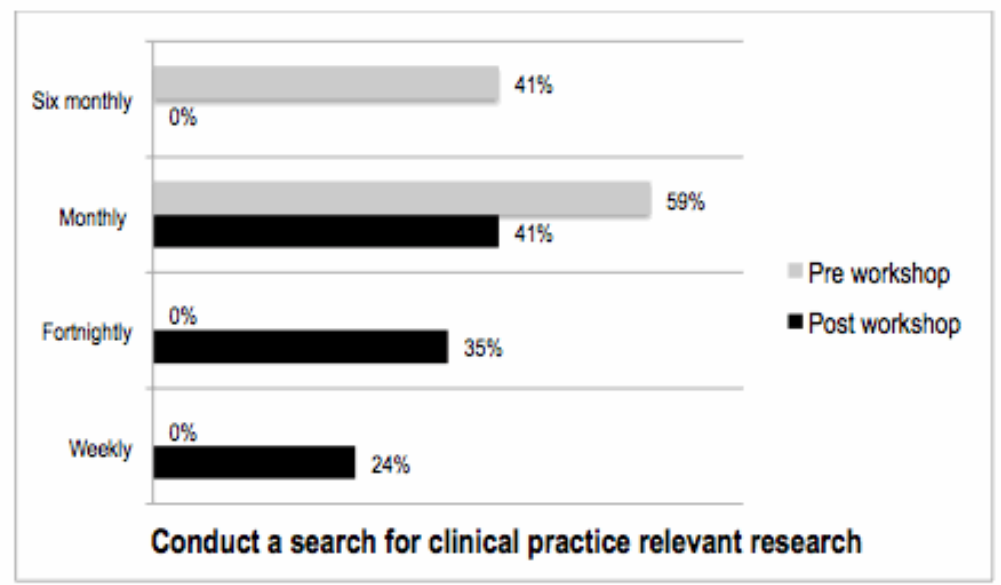


Prior to attending the workshop, all respondents reported searching either monthly or six monthly. After attending the EBP workshop, most participants reported undertaking searches for clinical practice relevant research on either a fortnightly or weekly basis.

\section{Figure 3. EBP Activity - Reading Research Literature Related to Clinical Practice}

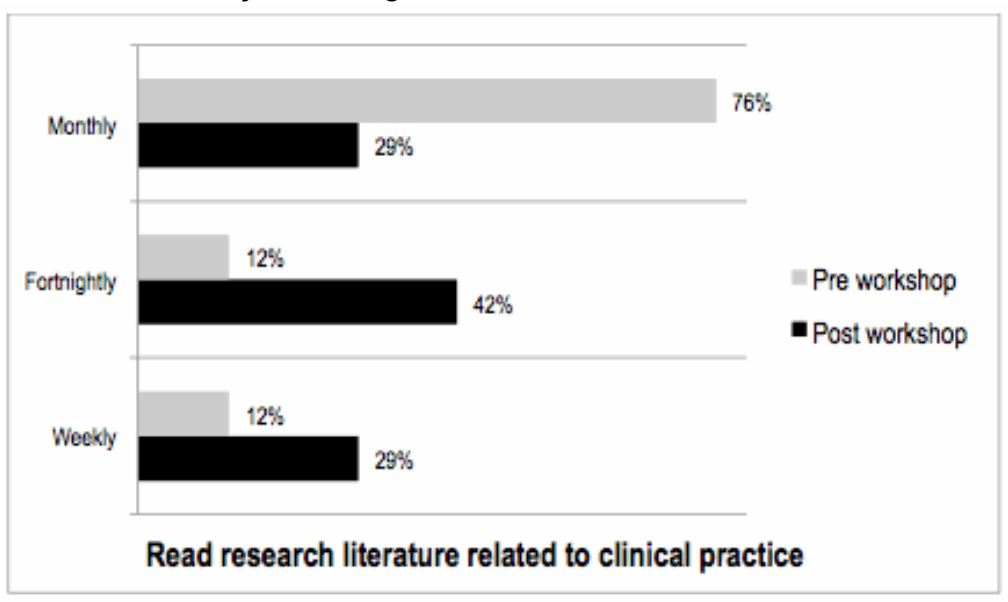

Pre-workshop survey data indicated that most participants were reading research literature related to clinical practice on a monthly basis. When participants were surveyed after attending the workshop most reported that they were undertaking this activity fortnightly. An increase was also seen in the number of participants reading research literature on a weekly basis.

\section{EBP Knowledge and Skills}

Figure 4. Self-Rated EBP Knowledge and Skills

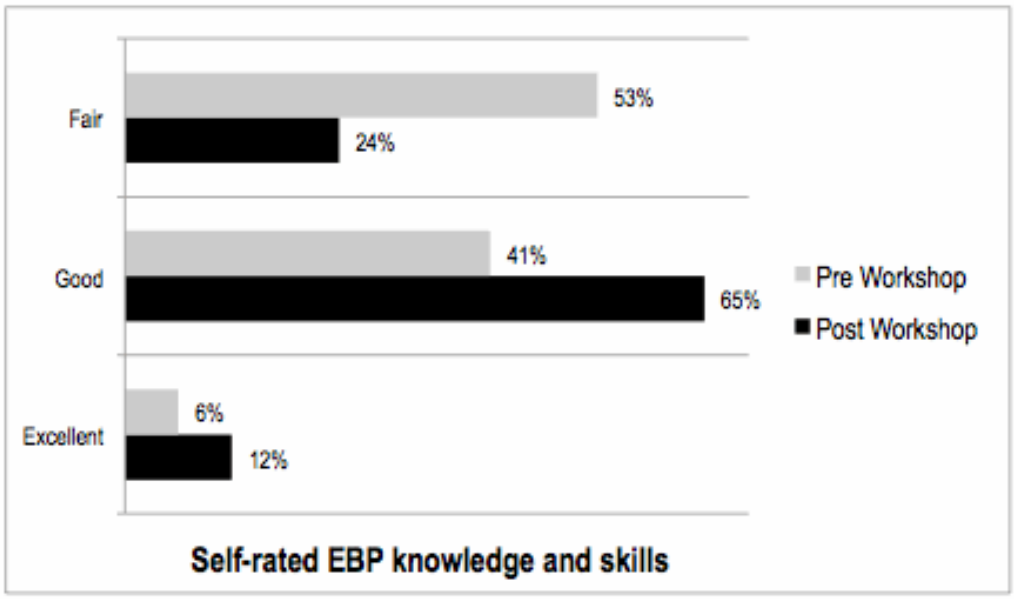

Prior to attending the EBP workshop most participants rated their knowledge and skills in EBP as only "fair." A positive shift in participants' self-reported knowledge and skills in EBP was observed with most participants rating their EBP knowledge and skills as "good" in the post workshop survey. 
EBP Attitudes and Beliefs

\section{Figure 5. The Use of EBP in Rehabilitative Physiotherapy Will Improve Patient Care}

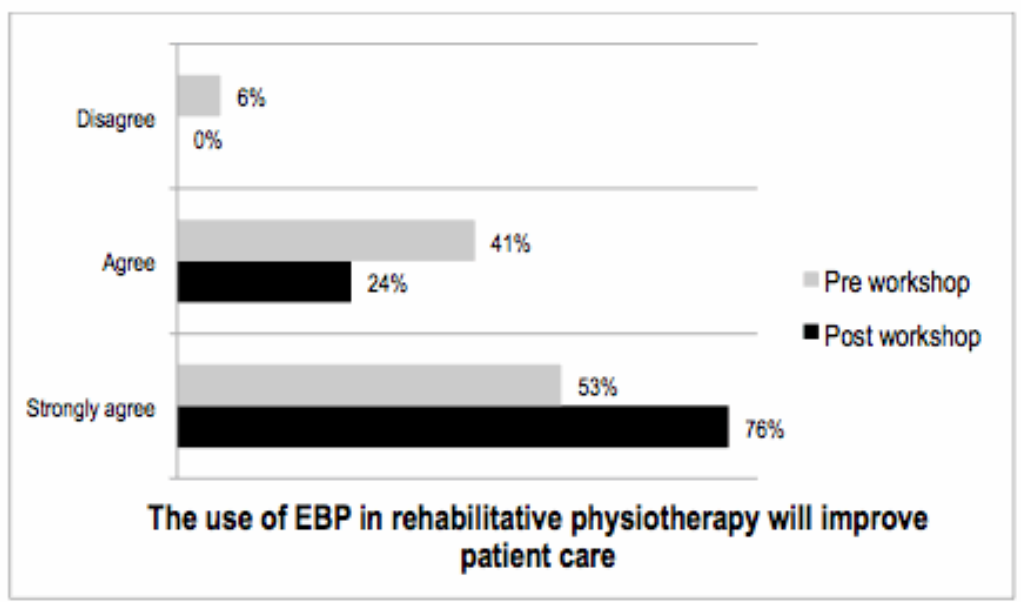

The post-workshop data revealed an increase of $23 \%$ in the number of participants who strongly agreed with the statement regarding the value of EBP, and that such an approach improves patient care when compare with the pre-workshop survey.

\section{EBP Barriers to application}

Figure 6. Greatest Barrier to the Application of EBP in Clinical Practice

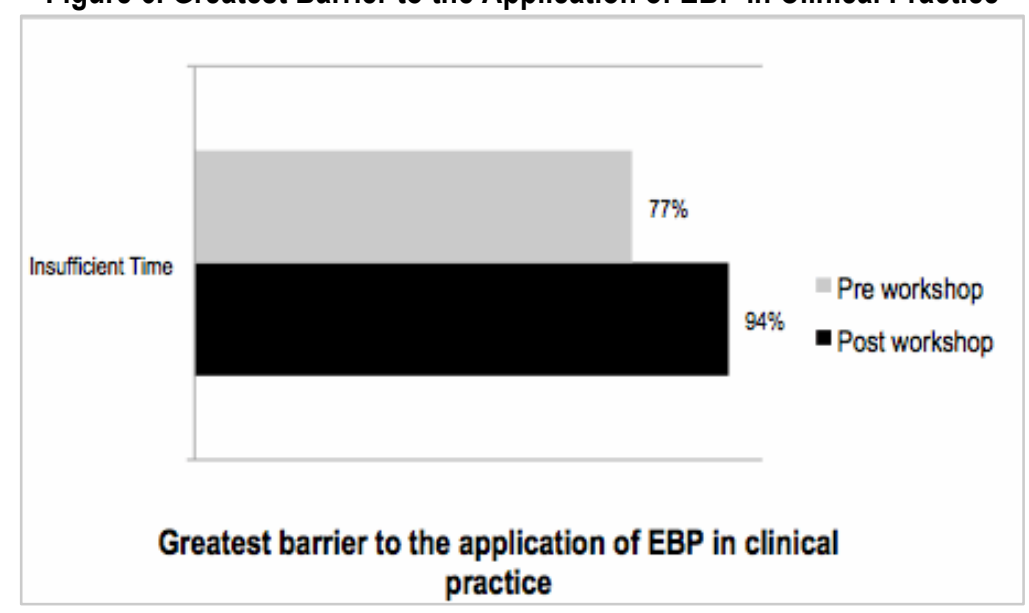

Across both surveys, participants reported that "insufficient time" was the primary barrier to the application of EBP in their clinical practice.

\section{DISCUSSION}

It has been suggested that improving EBP in clinical practice may rely on education and training in core EBP competencies including on-line database search skills and the ability to critically appraise literature in the context of clinical practice. ${ }^{3}$ This study examined whether participation in an EBP professional development workshop may address some of the specific EBP training and education challenges for physiotherapists and be an effective strategy in promoting the necessary EBP knowledge, skills, attitudes, and behaviours.

Following the workshop, participants were undertaking EBP activity including literature searching and reviewing relevant literature directly related to clinical practice on a more frequent basis, indicating that providing physiotherapists with specific EBP professional development does promote an increase in these specific EBP activities and behaviours. This data supports notions 
suggested by other authors that targeted EBP professional development, training, and education may have a positive influence on increasing the frequency of EBP activity undertaken by physiotherapists. $3,7-12,14,16$

Previous research has suggested dedicated EBP education and training leads to physiotherapist feeling more positive regarding their EBP knowledge and skills.3,16 Nearly a third of the physiotherapists surveyed indicated that their EBP knowledge and skills had increased following attendance at the EBP professional development workshop. It is likely that if clinicians have more confidence in their EBP skills and knowledge, they are likely to undertake EBP activity on a more frequent basis. It is probable that these clinicians will integrate EBP activity into clinical practice more regularly, resulting in both improved patient outcomes and further enhancement of their EBP knowledge and skills.1,12 The evidence suggests clinical integration of EBP training and education may have the greatest impact on improving EBP skills, attitudes, and behaviors. ${ }^{15}$ Physiotherapists should feel optimistic about undertaking EBP focused professional development activity in the clinical setting as a means to consolidate EBP skills and knowledge and contribute positively to clinical practice.

It is believed EBP attitudes and beliefs are related to both the local EBP culture as well as the allocation of resources directed towards enhancing the implementation of EBP. ${ }^{15-17}$ These factors should not be considered mutually exclusive. The current study illustrates that investment in EBP resources such as providing professional development opportunities can contribute to physiotherapists feeling more positive as to the potential benefits of an EBP approach which is likely to enhance and strengthen the local EBP culture.

In related studies where physiotherapists have been surveyed regarding EBP activity, insufficient time is consistently cited as the most significant barrier to EBP. ${ }^{2-4,6-17}$ Perhaps the greatest paradox in this study was that following the EBP workshop, there was an increase in the number of physiotherapists who reported that time was a barrier to implementing EBP in clinical practice. So, even with set time allocated to learn about EBP, develop the skills to conduct database searches, and learn how to formulate answerable clinical questions, physiotherapists still believed more time was required to successfully apply EBP in clinical practice. It would appear consolidating the various EBP components may take considerable time for physiotherapists, but it is likely that in the long term, they will be providing interventions that are more efficacious for patients. ${ }^{16}$

\section{Study Limitations}

The results revealed differences between response data after participants attended the EBP workshop. However, the results should be interpreted with some caution, as there may have been other factors that influenced the observed changes in survey response data. Firstly, the reliability of the survey was not tested. Secondly, it is plausible that the results from this study reflected a short-term increase in respondents EBP activity and behaviours. These limitations could be addressed by including reliability testing of the survey instrument, and incorporating a longer follow-up period.

Further research that aims to explore the generalisability of the findings from this study and any variations that may exist across different populations of physiotherapists should consider using a larger sample size.

\section{CONCLUSION}

The results from this study suggest that dedicated education and training in EBP through attendance and participation in an EBP professional development workshop may be an effective means for physiotherapists in the rehabilitation setting to acquire or extend their skills and knowledge of EBP. Insufficient time was reported by the majority of workshop participants as the primary barrier to the application of EBP in their clinical practice. Healthcare organisations that are intent on fostering a strong and sustainable EBP culture amongst their physiotherapists will need to focus on the necessary allocation of time and resources that may help address this obstacle. Further research is needed to objectively measure the effects of specific EBP professional development activities as a means of identifying which activities are most effective for the acquisition of EBP knowledge and skills. Equally as critical may be identifying the specific EBP activities that actually have the most impact on improving a physiotherapist's clinical practice and therefore the potential to enhance patient outcomes.

\section{ACKNOWLEDGEMENTS}

La Trobe University, School of Public Health, Melbourne, Australia; Royal Talbot Rehabilitation Centre (RTRC), Austin Health, Melbourne, Australia; Project Sponsor, Joan Stephens, Physiotherapy Manager RTRC; Study Participants, Physiotherapy Department, RTRC; Teaching Staff, La Trobe University, School of Public Health; Mr. Terry Harrison and Associate Professor Dr Peter Greenberg, Melbourne Health, Melbourne, Australia

\section{REFERENCES}

1. Sackett D, Straus S, Richardson S, Rosenberg W, Haynes R. Evidence-Based Medicine - How to Practice and Teach EBM, 2nd Edition. London: Churchill Livingstone;2000:5-7. 
2. Turner $P$, Whitfield TW. Physiotherapists' use of evidence-based practice: a cross-national study. Physiotherapy Research International. 1997;2(1):17-29. [PMID 9238748]

3. Iles R, Davidson M. Evidence-based practice: a survey of physiotherapists' current practice. Physiotherapy Research International. 2006;11(2): 93-103. [PMID 16808090]

4. Jette DU, Bacon K, Batty C, Carlson M, Ferland A, Hemingway RD, Hill JC, Ogilvie L, Volk D. Evidence-Based Practice: Beliefs, Attitudes, Knowledge and behaviours of Physical Therapists. Physical Therapy. 2003;83(9):786-805. [PMID 12940766]

5. Metcalfe C, Lewin R, Wisher S, Perry S, Bannigan K, Klaber Moffett J. Barriers to implementing the evidence base in four NHS therapies. Physiotherapy. 2001;87(8):433-41.

6. Kamwendo K. What do Swedish Physiotherapist feel about Research? A survey of perceptions, attitudes, intentions and engagement. Physiotherapy Research International. 2002;7(1):23-34.

7. Pomeroy VM, Tallis RC, Stitt E. Dismantling some barriers to Evidence-based Rehabilitation with 'Hands-on' Clinical Research Secondments. Physiotherapy. 2003;89(5):266-75.

8. Herbert R, Sherrington C, Maher C, Moseley A. Evidence-based practice: Imperfect but necessary. Physiotherapy Theory and Practice. 2001;17:201-11.

9. Schriber J, Stern P. A review of the literature on evidence-based practice in physical therapy. The Internet Journal of Allied Health Science and Practice. 2005;3(4);1-9.

10. O'Brien M. Keeping up-to-date: continuing education, practice improvement strategies and evidence-based physiotherapy practice. Physiotherapy Theory and Practice. 2001;17:187-99.

11. Morris J. Evidence-based practice the way forward. Physiotherapy. 2003;89(6):330-1.

12. Gibson B, Martin D. Qualitative research and evidence-based Physiotherapy Practice. Physiotherapy. 2003;89(6):350-8.

13. Maher CG, Sherrington C, Elkins M, Herbert RD, Moseley AM. Challenges for Evidence-Based Physical Therapy: Accessing and Interpreting High-Quality Evidence on Therapy. Physical Therapy. 2004;87(4):644-54. [PMID 15225083]

14. Turner P. Evidence-based practice and physiotherapy in the 1990's. Physiotherapy Theory and Practice. 2001;17:107-12.

15. Coomarasamy A, Khan KS. What is the evidence that postgraduate teaching in evidence-based medicine changes anything? A Systematic Review. British Medical Journal. 2004;329(7473):1017-21. [PMID 15514348]

16. Stevenson K, Lewis M, Hay E. Do physiotherapists' attitudes towards evidence-based practice change as a result of an evidence-based education programme? Journal of Evaluation in Clinical Practice. 2004;10(2):207-17. [PMID 15189387]

17. Salbach NM, Jagal SB, Korner-Bitenssky N, Rappolt S, Davis D. Practitioner and Organizational Barriers to Evidencebased Practice of Physical Therapists for People With Stroke. Physical Therapy. 2007;87(10):1284-303. [PMID 17684088] 


\section{APPENDIX A}

Survey

Staff Survey - Please complete all survey items

For the following items place a mark $邓$ in the appropriate box that indicates your response

\begin{tabular}{|c|c|c|c|c|c|c|}
\hline \multicolumn{7}{|c|}{ Current Evidence-based practice (EBP) activity } \\
\hline Please indicate how often you; & Daily & Weekly & Fortnightly & Monthly & $\begin{array}{l}\text { Six } \\
\text { monthly }\end{array}$ & Never \\
\hline \multicolumn{7}{|l|}{$\begin{array}{l}\text { (1) Use literature and research findings in the } \\
\text { process of clinical decision making }\end{array}$} \\
\hline \multicolumn{7}{|c|}{$\begin{array}{l}\text { (2) Conduct a search via an electronic database } \\
\text { for clinical practice relevant research }\end{array}$} \\
\hline \multicolumn{7}{|c|}{$\begin{array}{l}\text { (3) Read/review research literature related to my } \\
\text { clinical practice }\end{array}$} \\
\hline $\begin{array}{l}\text { (4) Refer to clinical practice guidelines for } \\
\text { topics/areas related to my clinical practice }\end{array}$ & & & & & & \\
\hline
\end{tabular}

\begin{tabular}{|l|l|l|l|l|}
\cline { 2 - 5 } Please indicate how often you; & All of the time & $\begin{array}{l}\text { Most of } \\
\text { the time }\end{array}$ & $\begin{array}{l}\text { Some of } \\
\text { the time }\end{array}$ & Never \\
\hline $\begin{array}{l}\text { (5) Use your initial physiotherapy training to guide treatment } \\
\text { selection in the clinical setting }\end{array}$ & & & & \\
\hline
\end{tabular}

\section{Perceived EBP skills}

\begin{tabular}{|l|l|l|l|l|}
\cline { 2 - 5 } \multicolumn{1}{l|}{} & $\begin{array}{l}\text { Strongly } \\
\text { agree }\end{array}$ & Agree & Disagree & $\begin{array}{l}\text { Strongly } \\
\text { disagree }\end{array}$ \\
\hline $\begin{array}{l}\text { (6) I am confident in my ability to find the best available evidence to } \\
\text { answer my clinical questions }\end{array}$ & & & & \\
\hline $\begin{array}{l}\text { (7) I have received formal training in search strategies for finding } \\
\text { research relevant to my clinical practice }\end{array}$ & & & & \\
\hline (8) I am confident in my ability to critically appraise research literature & & & & \\
\hline
\end{tabular}

(9) I would currently rate my EBP knowledge and skills as

\begin{tabular}{|l|l|l|l|}
\hline Excellent & Good & Fair & Poor \\
\hline & & & \\
\hline
\end{tabular}




\section{Recognition of EBP terminology and search strategies}

\begin{tabular}{|l|l|l|l|l|}
\cline { 2 - 5 } \multicolumn{1}{l|}{} & $\begin{array}{l}\text { Strongly } \\
\text { agree }\end{array}$ & Agree & Disagree & $\begin{array}{l}\text { Strongly } \\
\text { disagree }\end{array}$ \\
\hline $\begin{array}{l}\text { (10) I learned the foundations of EBP as part of my undergraduate } \\
\text { training }\end{array}$ & & & & \\
\hline
\end{tabular}

(11) My understanding of the following terms is:

\begin{tabular}{|l|l|l|l|l|}
\hline Term & $\begin{array}{l}\text { Understand } \\
100 \%\end{array}$ & $\begin{array}{l}\text { Understand } \\
\text { mostly }\end{array}$ & $\begin{array}{l}\text { Understand } \\
\text { A little }\end{array}$ & $\begin{array}{l}\text { Do not } \\
\text { understand }\end{array}$ \\
\hline Systematic Review & & & & \\
\hline Publication bias & & & & \\
\hline Meta Analysis & & & & \\
\hline External Validity & & & & \\
\hline Internal Validity & & & & \\
\hline
\end{tabular}

(12) I would rate my knowledge of evidence-based practice terminology as

\section{Beliefs and attitudes to EBP}

\begin{tabular}{|c|c|c|c|c|}
\hline & $\begin{array}{l}\text { Strongly } \\
\text { agree }\end{array}$ & Agree & Disagree & $\begin{array}{l}\text { Strongly } \\
\text { disagree }\end{array}$ \\
\hline $\begin{array}{l}\text { (13) I believe I should increase the use of EBP in my clinical } \\
\text { practice }\end{array}$ & & & & \\
\hline $\begin{array}{l}\text { (14) Using EBP in rehabilitative physiotherapy will improve the } \\
\text { quality of patient care }\end{array}$ & & & & \\
\hline $\begin{array}{l}\text { (15) I am interested in learning or improving the skills required to } \\
\text { incorporate EBP into my clinical practice }\end{array}$ & & & & \\
\hline
\end{tabular}

\begin{tabular}{|l|l|l|l|l|l|}
\cline { 2 - 6 } \multicolumn{1}{c|}{} & $\begin{array}{l}\text { Very } \\
\text { positive }\end{array}$ & Positive & $\begin{array}{l}\text { Not } \\
\text { sure }\end{array}$ & Negative & $\begin{array}{l}\text { Very } \\
\text { negative }\end{array}$ \\
\hline $\begin{array}{l}\text { (16) My attitude towards improving the use of EBP } \\
\text { principles within the physiotherapy department is }\end{array}$ & & & & & \\
\hline
\end{tabular}




\section{Local barriers to EBP}

For the following item, rank all items from 1-6 by placing a number in all boxes

(17) Please Rank these 6 items relating to barriers in the application of EBP in your clinical practice

(1=greatest barrier, $6=$ least important barrier)

\begin{tabular}{|l|l|}
\hline Item & Ranking \\
\hline Insufficient Time & \\
\hline Lack of EBP resources (i.e. computers/journal access) & \\
\hline Lack of generalisability of research findings to individual patients & \\
\hline Inability to critically appraise the research literature & \\
\hline Lack of EBP training and education & \\
\hline Lack of interest in EBP & \\
\hline
\end{tabular}

For the following item place a mark $\chi$ in the appropriate box that indicates your response

(18) From the same list of potential local EBP barriers indicate the ONE barrier that you feel the department should target to improve

\begin{tabular}{|l|l|}
\hline Item & $\begin{array}{l}\text { Target to improve } \\
\text { (Please Choose One item only) }\end{array}$ \\
\hline Insufficient Time & \\
\hline Lack of EBP resources (i.e. computers/journal access) & \\
\hline $\begin{array}{l}\text { Lack of generalisability of research findings to } \\
\text { individual patients }\end{array}$ & \\
\hline Inability to critically appraise the research literature & \\
\hline Lack of EBP training and education & \\
\hline Lack of interest in EBP & \\
\hline
\end{tabular}

\section{Demographic information}

For the following item place the year (i.e. 1997) in the appropriate box that indicates your response

Please indicate below the year in which you graduated as a physiotherapist

\begin{tabular}{|l|}
\hline Graduation Year \\
\hline \\
\end{tabular}

Thank You for your participation.

Before you return this survey please check you have completed all survey items. 


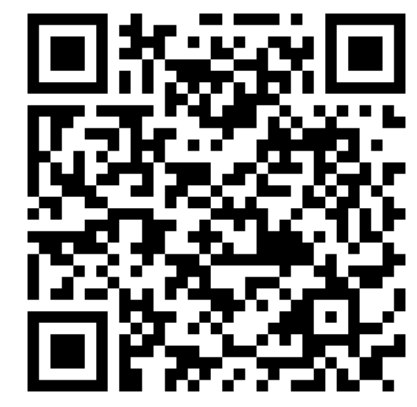

Manuscript on Web 